
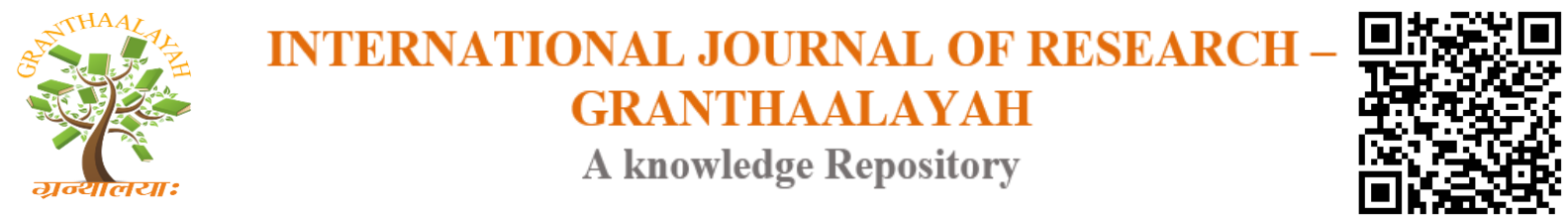

Science

\title{
EFFECT OF COMMUNITY BASED AREA-WIDE FRUIT FLY SUPPRESSION ON BACTROCERA DORSALIS POPULATION IN ORANGE ORCHARDS IN MUHEZA DISTRICT TANZANIA
}

\author{
Zuberi Singano Seguni ${ }^{* 1}$ \\ ${ }^{* 1}$ Mikocheni Agriculture Research Institute, P. O Box 6226, Dar es Salaam Tanzania
}

DOI: https://doi.org/10.29121/granthaalayah.v4.i9.2016.2532

\section{ABSTRACT}

A community-based area wide fruit fly suppression exercise involving simultaneous application by farmers of methyl eugenol-mediated mass capture of males of Bactrocera dorsalis fruit fly, crop sanitation by burial of fallen fruits and SUCCESS bait (GF 121)spot application of citrus tree crowns, was undertaken in three villages in Muheza district, Tanga region north eastern Tanzania. Male fruit fly numbers in methyl eugenol traps dropped significantly following application of the treatments from 970 flies per trap per week before application of treatments in July 2011 to 100 and 46 flies six and nine months after treatments at Kwabada village; 200 flies per trap per week before to 34 and one flies after treatment at Kwemsaa village and from 800 flies before to 64 and 50 flies per trap per week during the same period at Mlingano village. However, a fall occurred also in untreated orchards indicating a possible spill-over effect of the treatments due to the large area covered. Moreover, the treated areas might have acted as a sink that drew fruit flies from neighbouring untreated orchards into it. The drastic fall in trapped males may be associated with the effect of the treatments in reducing the number of flies so that fewer were available to fly into the traps. The collective and simultaneous application by farmers of fruit fly suppression over a large crop area is a robust strategy to manage fruit flies in citrus and other fruits orchards such as mango. The results suggest that farmers can successfully implement area-wide fruit fly suppression in smallholder citrus systems.

Keywords:

Community based area-wide suppression, Integrated Pest Management (IPM), Bactrocera dorsalis.

Cite This Article: Zuberi Singano Seguni, "EFFECT OF COMMUNITY BASED AREA-WIDE FRUIT FLY SUPPRESSION ON BACTROCERA DORSALIS POPULATION IN ORANGE ORCHARDS IN MUHEZA DISTRICT TANZANIA" International Journal of Research Granthaalayah, Vol. 4, No. 9 (2016): 39-44. 


\section{INTRODUCTION}

Bactrocera dorsalis Hendel (Diptera: Tephritidae), an exotic fruit fly pest of Asian origin, is among key constraints to profitable orange production in Muheza District, Tanga region Tanzania. In addition to its prolific reproductive potential in its new colonized land, the pest infests a wide range of cultivated and wild fleshy fruits including mangoes, guava, banana, tomato, avocado, marula etc. (Lux et al, 2003; Ekesi and Billah, 2007; Mwatawala et al., 2009). Infestation by the fruit fly is due to females laying eggs within fruits and damage done by maggots hatching therefrom feeding on the pulp. Most often infested fruits drop prematurely due to rotting. The fruit fly therefore reduces fruit quality and crop yields. It is also a quarantine pest which restricts international trade in fruits from countries where it occurs.

The Muheza district in Tanga region in north eastern Tanzania cultivates more than 7,000 ha of citrus yielding about 3.5 million fruits (approximately 240,000 tons) annually with an estimated gross value of seven billion Tanzanian shilling (TAS) (Muheza District Council, 2008). In the 2009/10 citrus season, crop loss due to fruit fly damage to oranges and premature fruit dropping was estimated to be 1.5 million fruits valued at TAS 1.7 billion (Muheza District Council, 2010). The fruit fly had been in the country since end of 2003 (Mwatawala, et al 2009; Seguni et al, 2004; Lux et al, 2003). In 2008, farmers in three key citrus growing villages; Mlingano, Kwemsaa and Kwabada in the district requested intervention to overcome massive premature dropping of oranges associated with $B$. dorsalis infestation, which they had observed on ripening oranges. $B$. dorsalis involvement was also supported by the trapping of large numbers of the fruit fly in methyl eugenol traps in expansive orange orchards in the same villages during mango off season period. A project to suppress the fruit fly and thus relieve farmers from the fruit fly problem through a community-based and area-wide approach in the three villages was executed with funds from the Eastern Zone Research Fund (ZARDEF) starting from June 2011. The suppression was executed by communities of the targeted villages acting at the same time in applying a package of IPM components on adjoining citrus orchards at the start of the orange season and at intervals thereafter until the end of the season.

\section{MATERIALS AND METHODS}

\subsection{FRUIT FLY IPM IMPLEMENTING FARMERS' GROUPS}

In each village, small-scale growers with neighbouring citrus orchards totaling 60 to 100 acres were voluntarily organized in IPM groups of 25 mixed sex and ages members each for collective and simultaneous application of the following IPM technologies:

i) Orchard sanitation: done by weekly collection and burial of fallen fruits in pits dug in the ground measuring $3 \times 3$ meters in depth and width;

ii) Mass annihilation of males of $B$. dorsalis fruit fly by attracting them into methyl eugenol traps improvised by farmers from discarded $500 \mathrm{ml}$ mineral water bottles which were distributed in the fields at the density of three traps per acre and replenished with methyl eugenol every two months. Methyl eugenol was poisoned with Dichlorvos (Nuvan 50\% ec) at the ratio of ten parts of methyl eugenol to one part of insecticide. Four milliliters of toxic methyl eugenol was 
imbibed onto a cylindrical cotton wool dental roll measuring $4 \times 1 \mathrm{~cm}$ hung in the bottle trap by a $13 \mathrm{~cm}$ long string. The bottle had three $2 \mathrm{~cm}$ wide fly entry perforations around the upper one third of its body.

Traps were hung by thin but strong $30 \mathrm{~cm}$ long strings on orange trees three meters above ground and inspected at week intervals during which time trapped fruit flies were recorded. Trap positions were chosen such that the traps were fully exposed to fruit flies while ensuring that minimum direct sunlight reached them to minimize rapid evaporation of methyl eugenol. Fruit flies were collected by respective farmers under supervision of extension officers and numbers were compiled weekly and pooled for each of the three months trapping duration and expressed as fruit flies/trap/week.

iii) Spot application of SUCCESS bait (GF 121) was done on tree crowns of alternating rows of citrus at 10-12 days intervals by spraying one meter square spots of a mixture of SUCCESS bait diluted at the ratio of 1:20 i.e. bait to water. Spraying was done using a shoulder-carried knapsack sprayer, CP Cooper Pegler 100, issuing coarse droplets $4 \mathrm{~mm}$ in diameter directing the nozzle to underside of leaves to ensure longevity of bait. Only $50 \mathrm{ml}$ of bait mixture was sufficient for treating one crown spot on each treated tree. Untreated control orchards were situated about one kilometer away from treatment orchards to minimize drift and only methyl eugenol traps were installed for monitoring purposes.

\subsection{FRUIT INFESTATION BY B. DORSALIS}

To measure fruit fly damage, fruit samples of three developmental stages: (i) egg-size fruits about $4-5 \mathrm{~cm}$ diameter) (ii) mid-season fruits $(5-7 \mathrm{~cm}$ diameter) and (iii) mature and ripening fruits (7-8 cm diameter) were used. Fifty fruits were collected from each of 10 orchards per village in June 2011, September 2011 and February 2012. Fruits were secured in polythene bags and incubated at MARI laboratory in 4 litre plastic food containers or 20 litre buckets, one thirdfilled with heat $\left(60^{\circ}-70^{\circ} \mathrm{C}\right)$ sterilized sand and covered with mosquito netting, until rotting ensued. Each fruit was dissected individually and all infesting maggots were carefully removed from the pulp and incubated in similar containers until pupation and eclosion. Adult flies were identified at MARI to genus and species levels for common fruit flies. Uncommon fruit flies were sent to in-country experts or abroad for more expert identification. Specimens were preserved in $70 \%$ ethyl alcohol. Chi square test was used to compare effect of treatments. This short paper reports only on fruit fly population trend in response to application of fruit fly suppression technologies.

\section{RESULTS}

\subsection{MALE FRUIT FLY CATCHES IN METHYL EUGENOL TRAPS IN IPM TREATED AND UNTREATED ORCHARDS BETWEEN JUNE 2011 AND MARCH 2012}

Only males of B. dorsalis were, as expected, attracted to methyl eugenol. Highest catches of 965 male fruit flies per trap per week were at Kwabada village in July 2011 at start of suppression, followed by Mlingano and Kwemsaa villages with 800 and 200 male flies, respectively (Table 1). Between September and December 2011 following application of IPM technologies to 
suppress the fruit fly, numbers of $B$. dorsalis male fruit flies in traps decreased sharply to 100 flies per trap per week at Kwabada, 64 at Mlingano and 34 at Kwemsaa (Table 2). At the end of the season between January and March 2012, fruit fly numbers continued to fall sharply to 46 at Kwabada, 53 at Mlingano and one at Kwemsaa (Table 3). In untreated control orchards fruit fly numbers at the start of the suppression trial were as high as in the orchards designated for suppression (Table 2). Similarly, following application of treatments a drastic fall in numbers occurred from 850 to 150 between September and December 2011 which continued further to 52 flies per trap per week in the period towards the end of the season between January and March 2012 (Table 2 and 3). Decreases in male fruit flies trapped in methyl eugenol were statistically significant at both 95 and $99 \%$ probability levels whereby the calculated $\chi^{2}=47.02$ at $6 \mathrm{df}$, which is much higher than the tabulated values of between 12.59 and 16.81, respectively. Methyl eugenol traps attracted neither other fruit flies nor other insects

\section{DISCUSSION}

Results above show that $B$. dorsalis fruit fly population expressed as fruit fly catches per trap per week, was significantly affected by suppression measures undertaken by farmers and was highly lowered in all treatment orchards. Fruit fly catches per trap per week at Kwemsaa at the start of the suppression were lower than at other sites presumably due to a higher trap density as the orchards were closer to one another, thus spreading out the catches between the traps.

At all sites, fruit fly catches per trap per week between January and March 2012 were lower than those in July 2011 and September-December 2011, presumably due to reductions in the male population in the treated fields. On untreated orchards, numbers of B. dorsalis male fruit flies per trap per week were similar to those in treatment plots before the start of suppression. It would be expected that similar declines occurred on the female $B$. dorsalis population and a corresponding decline in damage to oranges.

Male B. dorsalis catches between January and March 2012 were in general very low at all sites (Tables 2 and 3). This period coincided with depletion of breeding substrates at the end of the current orange season and beginning of the new season. The period also coincided with the end of the mango season at the peak of which fruit fly numbers increased markedly, mango being the second most preferred host after Indian almond (Lux et al. 2003). In the untreated orchards, unfortunately, the drop in trap catches was similar to treated orchards, which could have been due to drift of the treatments to untreated orchards in spite of their separation by one kilometer distance. The treatment orchards could also have created a "sink effect" for the fruit fly, which could draw it from untreated orchards and presumably getting killed in the treatment orchards on toxic bait and by being trapped in toxic methyl eugenol.

That the declining numbers of the male fruit fly in treated orchards could be associated with the suppression exercise arises partly from the fact that the population would normally be expected to rise with maturation of oranges between January and March through to June 2012 as the fruits increased in attractiveness to fruit flies, which was contrary. A similar B. dorsalis population trend was observed in mango small-holder systems in Tanzania where following application of same suppression technologies, the population of male fruit flies in methyl eugenol traps decreased as the mango season progressed contrary to what would normally be expected without 
suppression intervention when numbers would be expected to increase dramatically as the maturing mangoes became increasingly attractive to the fruit fly (Materu et al, 2014).

These results therefore demonstrate the effect and success of a large scale $B$. dorsalis trapping exercise in combination with the application of other mutually complementary fruit fly suppression strategies. It is presumed that the fruit fly population in the trial villages was compounded by availability of mangoes during the June-August period in which $B$. dorsalis multiplied rapidly before moving into citrus orchards, although citrus is not its most preferred host.

\section{CONCLUSION AND RECOMMENDATIONS}

In conclusion, these results demonstrate the effectiveness of large scale $B$. dorsalis suppression in smallholder citrus cropping by using a combination of fruit fly suppression strategies, which was undertaken by small-scale farmers acting together at the same time in applying the technology over a large crop area. It is presumed that other fruit farmer in other villages could act in the same way to suppress $B$. dorsalis or similar fruit flies on citrus or other similarly affected fruits for production of larger volumes of high quality fruits for domestic and trade purposes.

\section{Table 1:}

Mean numbers of Bactrocera dorsalis males/trap/week collected in methyl eugenol traps in citrus orchards prior to application of IPM technonologies to suppress the fruit fly at Kwabada, Mlingano and Kwemsaa villages in July 2011

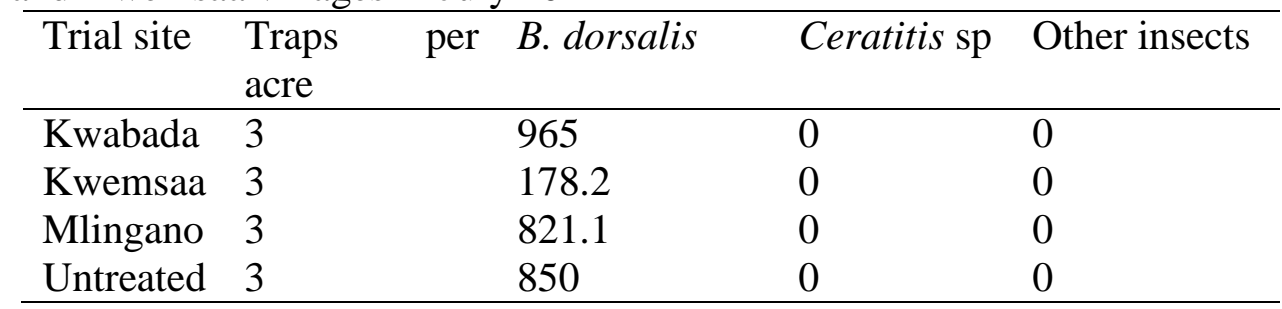

\section{Table 2:}

Mean numbers of Bactrocera dorsalis males/trap/week collected in methyl eugenol traps in citrus orchards where IPM technonologies were applied by farmers to suppress the fruit fly at Kwabada, Mlingano and Kwemsaa villages between September and December 2011

\begin{tabular}{|c|c|c|c|c|c|}
\hline Trial site & $\begin{array}{l}\text { Traps } \\
\text { acre }\end{array}$ & per & B. dorsalis & Ceratitis $\mathrm{sp}$ & Other insects \\
\hline Kwabada & 3 & & 104.7 & 0 & 0 \\
\hline Kwemsaa & 3 & & 33.9 & 0 & 0 \\
\hline Mlingano & 3 & & 63.6 & 0 & 0 \\
\hline Untreated & 3 & & 150 & 0 & 0 \\
\hline
\end{tabular}

\section{Table 3:}

Mean numbers of Bactrocera dorsalis males/trap/week collected in methyl eugenol traps in citrus orchards where IPM technonologies were applied by farmers to suppress the fruit fly at Kwabada, Mlingano and Kwemsaa villages between January and March 2012 


\begin{tabular}{|c|c|c|c|c|}
\hline Trial site & $\begin{array}{l}\text { Traps per } \\
\text { acre }\end{array}$ & B. dorsalis & Ceratitis $\mathrm{sp}$ & Other insects \\
\hline Kwabada & 3 & 45.8 & 0 & 0 \\
\hline Kwemsaa & 3 & 1.1 & 0 & 0 \\
\hline Mlingano & 3 & 52.9 & 0 & 0 \\
\hline Untreated & 3 & 52 & 0 & 0 \\
\hline
\end{tabular}

\section{ACKNOWLEDGEMENTS}

Many thanks are to the ZARDEF Eastern Zone and the Ministry of Agriculture Livestock and Fisheries for financing the research activities. Thanks are also to different farmers and extension staff in project areas for cooperation. Last but not least to my colleagues in Pest Control Unit: Valentina Nyange, B. Mruma, the Late Ntuli Swila and collaborators in Muheza District DALDOs office in particular Nahida Mbwana, Mr Shore and Mrs Mrinji for dedication to the project.

\section{REFERENCES}

[1] S. Ekesi and M. K. Billah, (2007). A Field Guide to the Management of Economically Important Tephritid Fruit Flies in Africa; Second Edition $61 \mathrm{pgs}$

[2] Lux S. A, Copeland R. S, White I. M, Manrakhan A, and Billah, M. K (2003). A new invasive fruit fly species from the Bactrocera dorsalis Hendel Group detected in East Africa. Insect Science and Its Application 23 355-361

[3] Materu L.C, Z. S. Seguni, Evarista E Shao, Beatrice M. Mruma and Andrew Ngereza, (2014). Assessing the impact of Integrated Pest Management programme for management of fruit flies (Diptera: Tepheritidae) on mango orchards in Tanzania. Agricultural and Environmental Sciences Vol 1, Issue-2Pages 38-_

[4] Muheza District Council Annual Report 2008

[5] Muheza District Council Annual Report 2010

[6] Mwatawala M.W, De Meyer M, Maundi, R. H and Maerere A. P (2009). Host range and distribution of fruit-infesting pestiferous fruit flies (Diptera:Tephritidae) in selected areas of Central Tanzania. Bulletin of Entomological Research doi: 10.1017/50007485309006695 (e publication)

[7] Seguni Z. S. K, Mwaiko, W and Holler, T (2004). A survey of five mango regions of mainland Tanzania to verify presence of the Oriental fruit fly Bactrocera dorsalis Hendel (Unpublished) 